\title{
Effect of Non-Thermal Product Energy Distributions on Ketohydroperoxide Decomposition Kinetics
}

\author{
C. Franklin Goldsmith, Michael P. Burke, Yuri Georgievskii, Stephen J. Klippenstein ${ }^{*}$ \\ Chemical Sciences and Engineering Division \\ Argonne National Laboratory \\ Argonne, IL, 60439, USA
}

*Corresponding author. Fax: +1 630 252-9292. E-mail address: sjk@anl.gov.

Colloquium: Reaction Kinetics

Main text:

Equation 1: $(1+2)$ lines $\times 7.6 \times 1$ column $=$ Equation 2: $(1+2)$ lines $\times 7.6 \times 1$ column $=$ Equation 3: $(1+2)$ lines $\times 7.6 \times 1$ column $=$ Equation 4: $(2+2)$ lines $\times 7.6 \times 1$ column $=$ Table 1: $(9+2)$ lines $\times 7.6 \times 1+14=$

Figure 1: $(90 \mathrm{~mm}+10) \times 2.2 \times 2+32=$

Figure 2: $(67 \mathrm{~mm}+10) \times 2.2 \times 1+49=$

Figure 3: $(67 \mathrm{~mm}+10) \times 2.2 \times 1+34=$

Figure 4: $(40 \mathrm{~mm}+10) \times 2.2 \times 1+52=$

Figure 5: $(90 \mathrm{~mm}+10) \times 2.2 \times 2+41=$

References: $(16$ references +2$) \times 2.3 \times 7.6=$

Non-text words $=$

Total Word count (excluding abstract):
3712 words

23 words

23 words

23 words

30 words

98 words

472 words

218 words

203 words

162 words

481 words

315 words

2048 words

5760 words 


\begin{abstract}
The decomposition of ketohydroperoxides $\left(\mathrm{OQ}^{\prime} \mathrm{OOH}\right)$ to two radicals is commonly predicted to be the key chain branching step in low-temperature combustion. The possibility of a direct decomposition of the $\mathrm{OQ}^{\prime} \mathrm{OOH}$ from its initially produced energy distribution is studied with a combination of master equation (ME) and direct trajectory simulations. The temperature and pressure dependent rate constants for the thermal decomposition of a ketohydroperoxide, $\mathrm{HOOCH}_{2} \mathrm{CH}_{2} \mathrm{CHO}_{\text {, to }}$ four product channels were computed using RRKM/ME methods. Direct dynamics calculations were initiated from a transition state in the $\mathrm{O}_{2}+$ QOOH reaction network to understand the fraction of energy in that transition state that is converted into the internal energy of the OQ'OOH. A novel approach to solving the master equation is used to determine the probability that a vibrationally hot $\mathrm{OQ}^{\prime} \mathrm{OOH}$ either will be stabilized to a thermal distribution or will react to form new products. Under most conditions, the majority of vibrationally excited $\mathrm{OQ}^{\prime} \mathrm{OOH}$ will be quenched into a thermal distribution. At higher internal energies and lower pressures, however, a significant fraction of the hot $\mathrm{OQ}^{\prime} \mathrm{OOH}$ will decompose rather than thermalize. Proper interpretation of low-pressure experiments may require inclusion of vibrationally hot intermediates, particularly if a chemical kinetic mechanism is optimized against the low-pressure data.
\end{abstract}

Keywords: low-temperature ignition, propane oxidation, master equation, direct dynamics, nonBoltzmann effects. 


\section{Introduction}

In the low-temperature oxidation of alkanes, an alkyl radical, $\mathrm{R}$, reacts with molecular oxygen to form an alkylperoxy radical, $\mathrm{RO}_{2}$. Depending upon the temperature and pressure, some of the $\mathrm{RO}_{2}$ will decompose to form a mixture of $\mathrm{HO}_{2}+$ alkene, $\mathrm{OH}+$ cyclic-ether, or $\mathrm{OH}+$ carbonyls. In the context of chain branching, however, the most important product from $\mathrm{RO}_{2}$ is a transient hydroperoxyalkyl radical, QOOH, which is formed via internal H-abstraction. A second oxygen molecule can add to the QOOH, thereby forming a hydroperoxyalkylperoxy radical, $\mathrm{O}_{2} \mathrm{QOOH}$. When this $\mathrm{O}_{2} \mathrm{QOOH}$ undergoes a similar internal $\mathrm{H}$-abstraction reaction, $\mathrm{TS}_{1}$ in Figure 1, the incipient alpha-hydroperoxy structure is not stable and immediately dissociates to form a ketohydroperoxide $+\mathrm{OH}$. The $\mathrm{O}-\mathrm{O}$ bond in the ketohydroperoxide $\left(\mathrm{OQ}^{\prime} \mathrm{OOH}\right)$ is relatively weak - typically on the order of $40-45 \mathrm{kcal} / \mathrm{mol}$ - and thus the $\mathrm{OQ}^{\prime} \mathrm{OOH}$ dissociates to form a ketoalkyloxy radical $+\mathrm{OH}\left(\mathrm{OQ}^{\prime} \mathrm{O}+\mathrm{OH}\right)$. This final reaction is chain branching. For a review of low-temperature oxidation, see Reference [1].

The $\mathrm{OQ}^{\prime} \mathrm{OOH}$ dissociation products are exothermic relative to the $\mathrm{O}_{2}+\mathrm{QOOH}$ reactants. For the n-propyl oxidation system, the zero-point corrected electronic energy of $\mathrm{HOOCH}_{2} \mathrm{CH}_{2} \mathrm{CHO}+\mathrm{OH}$ channel is $61 \mathrm{kcal} / \mathrm{mol}$ below $\mathrm{O}_{2}+\mathrm{CH}_{2} \mathrm{CH}_{2} \mathrm{CH}_{2} \mathrm{OOH}$, and the energy for the corresponding $\mathrm{OCH}_{2} \mathrm{CH}_{2} \mathrm{CHO}+2 \mathrm{OH}$ products is $17 \mathrm{kcal} / \mathrm{mol}$ below the same reactants [2]. Although the preceding reactions were described sequentially, chemically activated reactions can skip some of the intermediate steps, e.g. $\mathrm{R}+\mathrm{O}_{2} \rightarrow \mathrm{QOOH}$, and $\mathrm{O}_{2}+\mathrm{QOOH} \rightarrow \mathrm{OQ}^{\prime} \mathrm{OOH}+\mathrm{OH}$. In fact, owing to the exothermicity of the final products, some of the $\mathrm{O}_{2}+\mathrm{QOOH}$ may go directly to the three radicals in a single step: $\mathrm{O}_{2}+$ $\mathrm{QOOH} \rightarrow \mathrm{OQ}^{\prime} \mathrm{O}+2 \mathrm{OH}$.

Under typical conditions for low-temperature compression ignition engines (e.g. $700 \mathrm{~K}$ and 10 atm), several intermediates in the preceding reactions will reach a pseudo-steady state in which the net rate of destruction equals the net rate of formation $[3,4]$. First, the concentration of QOOH increases until the net rate for $\mathrm{O}_{2}+\mathrm{QOOH} \rightarrow$ products equals the net rate for $\mathrm{RO}_{2} \rightarrow \mathrm{QOOH}$; at the same time, the concentration of $\mathrm{R}$ builds up until the net rate for $\mathrm{R}+\mathrm{O}_{2} \rightarrow$ products equals the net rate for $\mathrm{RH}+$ 
$\mathrm{OH} \rightarrow \mathrm{R}+\mathrm{H}_{2} \mathrm{O}$; next, the concentration of $\mathrm{O}_{2} \mathrm{QOOH}$ increases until the net rate of $\mathrm{O}_{2} \mathrm{QOOH} \rightarrow$ $\mathrm{OQ}^{\prime} \mathrm{OOH}+\mathrm{OH}$ equals the net rate of $\mathrm{O}_{2}+\mathrm{QOOH} \rightarrow \mathrm{O}_{2} \mathrm{QOOH}$; lastly, the concentration of $\mathrm{OQ}^{\prime} \mathrm{OOH}$ builds up until its net rate of thermal decomposition equals the net rate of $\mathrm{O}_{2} \mathrm{QOOH}$ dissociation. Once this final stage has occurred, the sequence reaches a tipping point and becomes autocatalytic in radical production: the net result is two $\mathrm{OH}$ and one $\mathrm{OQ}^{\prime} \mathrm{O}$ formed for one $\mathrm{OH}$ consumed. Using a lowtemperature propane oxidation mechanism [5], Merchant et al. developed a simple-yet-accurate analytic model for first-stage ignition from these pseudo-steady state assumptions [3]. This model highlights the centrality of $\mathrm{OQ}^{\prime} \mathrm{OOH}$ in the low-temperature chain branching sequence and indicates that thermal decomposition of $\mathrm{OQ}^{\prime} \mathrm{OOH}$ is even the rate-determining step in first-stage ignition under some conditions.

The mechanism utilized in Reference 3 does not include other reactions for OQ'OOH destruction. If there were competing reactions that consumed $\mathrm{OQ}^{\prime} \mathrm{OOH}$ prior to its thermal decomposition to $\mathrm{OQ}^{\prime} \mathrm{O}+$ $\mathrm{OH}$, then these reactions could have a profound impact on the time constant for the first-stage ignition. Recently Jalan et al. discovered such a reaction [6]. The same ketohydroperoxide resulting from the npropyl system, $\mathrm{HOOCH}_{2} \mathrm{CH}_{2} \mathrm{CHO}$, can isomerize to form a cyclic peroxide, c- $\mathrm{CH}(\mathrm{OH}) \mathrm{OOCH}_{2} \mathrm{CH}_{2}(\mathrm{CP})$, which subsequently decomposes to a mixture of carboxylic acids and carbonyls, e.g. the blue lines in Figure 1.

This pathway, originally hypothesized by Korcek, is important in liquid-phase hydrocarbon oxidation [7,6]. The barrier height for isomerization from $\mathrm{OQ}^{\prime} \mathrm{OOH}$ to $\mathrm{CP}$ is $15 \mathrm{kcal} / \mathrm{mol}$ below the dissociation limit for the competing $\mathrm{OQ}^{\prime} \mathrm{O}+\mathrm{OH}$ chain branching pathway. Furthermore, the $\mathrm{OQ}^{\prime} \mathrm{OOH}$ $\rightarrow \mathrm{CP}$ isomerization reaction can be catalyzed by carboxylic acids, with a bimolecular barrier height of 1 $\mathrm{kcal} / \mathrm{mol}$ [6], so once a critical concentration of acids is obtained, the isomerization reaction becomes autocatalytic. However, both the unimolecular and the acid-catalyzed isomerization reactions involve the coordinated shuttling of two hydrogen atoms, which requires double ring-like structures, and thus represent a much greater loss of entropy as compared to the simple homolytic cleavage of the O-O bond 
in the competing decomposition reaction. Jalan et al. computed the high-pressure limit rate constant for the $\mathrm{OQ}^{\prime} \mathrm{OOH} \rightarrow \mathrm{CP}$ reaction and compared it with the high-pressure limit rate constant for dissociation provided in Reference 2 . Above $400 \mathrm{~K}$, the entropic penalty in the ring-closing transition state was sufficiently high to overcome the $15 \mathrm{kcal} / \mathrm{mol}$ advantage in enthalpy, and the Korcek pathway was effectively shut down. However, decreasing pressures increasingly favors the lowest threshold channels, and so this transition temperature may be considerably higher at real pressures. To the best of our knowledge, no master equation studies have looked at the pressure dependence of the competing OQ'OOH reaction pathways.

As mentioned above, since the $\mathrm{OQ}^{\prime} \mathrm{OOH}$ dissociation threshold is below $\mathrm{O}_{2}+\mathrm{QOOH}$ in energy, it is possible to skip OQ'OOH entirely, with effective phenomenological rate constants for $\mathrm{O}_{2}+\mathrm{QOOH}$ $\rightarrow \mathrm{OQ}^{\prime} \mathrm{O}+2 \mathrm{OH}$ and $\mathrm{O}_{2} \mathrm{QOOH} \rightarrow \mathrm{OQ}^{\prime} \mathrm{O}+2 \mathrm{OH}$ (or to proceed along the Korcek pathway). In the $\mathrm{QOOH}+\mathrm{O}_{2}$ rate coefficient study of Ref. 2, it was assumed that the fraction of $\mathrm{O}_{2}+\mathrm{QOOH}$ that was not stabilized to $\mathrm{O}_{2} \mathrm{QOOH}$ had sufficient thermal energy to go directly to $\mathrm{OQ}^{\prime} \mathrm{O}+2 \mathrm{OH}$, whereas the pathway from $\mathrm{O}_{2} \mathrm{QOOH}$ to $\mathrm{OQ}^{\prime} \mathrm{O}+2 \mathrm{OH}$ was assumed to proceed sequentially through $\mathrm{OQ}^{\prime} \mathrm{OOH}$. In reality, neither assumption is completely accurate, since in each case - whether starting with $\mathrm{O}_{2}+$ QOOH or with $\mathrm{O}_{2} \mathrm{QOOH}$ - the products leaving $\mathrm{TS}_{1}$ have a distribution of internal energy, some of which will be enough to directly dissociate, and some of which will not. Furthermore, QOOH itself may be produced in a vibrationally excited state from the $\mathrm{R}+\mathrm{O}_{2}$ reaction, and if this hot QOOH is intercepted by a second $\mathrm{O}_{2}$ before it can be stabilized by a non-reactive collision, then some of this excess energy will be converted into additional energy in the OQ'OOH.

The fate of this hot $\mathrm{OQ}^{\prime} \mathrm{OOH}$ depends upon whether or not it exists long enough to be quenched to a thermal distribution before it can dissociate. Accurate determination of this branching fraction is complicated by the presence of $\mathrm{OH}$ as a co-product, since some of the energy leaving $\mathrm{TS}_{1}$ will go into $\mathrm{OH}$ internal energy, and some will go into relative translational energy between the two fragments. The structure of the $\mathrm{OQ}^{\prime} \mathrm{OOH}$ fragment within transition state $\mathrm{TS}_{1}$ is considerably different from the global 
minimum geometry of $\mathrm{OQ}^{\prime} \mathrm{OOH}$, which implies that there must still be strong forces on the fragments as they depart the transition state. These strong forces imply that simple statistical arguments based on the total number of modes available for energy distribution may not be applicable.

In the present work, direct dynamics calculations are performed to quantify the percentage of total energy leaving $\mathrm{TS}_{1}$ that is converted into internal energy in $\mathrm{OQ}^{\prime} \mathrm{OOH}$. These calculations are then coupled with a recently developed master equation based methodology for predicting the branching ratio between the possible product channels for a given energy distribution of internally excited $\mathrm{OQ}^{\prime} \mathrm{OOH}$. The latter calculations are performed with our new master equation code, PAPER (for Predictive Automated Phenomenological Elementary Rates) [8,9], and employ the $\mathrm{C}_{3} \mathrm{H}_{6} \mathrm{O}_{3}$ potential energy surface considered in References 2,3,5,6. The analysis presented in this manuscript begins with the energy leaving $\mathrm{TS}_{1}$; in other words, it is agnostic with respect to the energy distribution of QOOH prior to its reaction with $\mathrm{O}_{2}$. The role of hot QOOH in the formation and decomposition of OQ'OOH is addressed in a companion paper [10].

\section{Methods}

\section{electronic structure}

The $\mathrm{C}_{3} \mathrm{H}_{7} \mathrm{O}_{4}$ potential energy surface (PES) is presented in Figure 1. The key transition state, $\mathrm{TS}_{1}$, is a six-membered ring in which the peroxy group abstracts a hydrogen from the carbon that is bound to the hydroperoxyl moiety to form $\mathrm{HOOCH}_{2} \mathrm{CH}_{2} \mathrm{CHOOH}$, which is not stable and immediately dissociates to $\mathrm{HOOCH}_{2} \mathrm{CH}_{2} \mathrm{CHO}+\mathrm{OH}$. The post-Hartree-Fock wave-function methods used in Reference 2 lack analytical gradients and would be computationally prohibitive for direct dynamics. Instead, density functional theory was used to compute the potential energy at each time step. The M062X functional [11] with a double-zeta basis set, 6-31+G(d,p), was chosen as a suitable compromise between efficiency and accuracy. All dynamics calculations were done using the Born-Oppenheimer Molecular Dynamics (BOMD) subroutine in Gaussian-09 [12]. The initial geometry for $\mathrm{TS}_{1}$ was taken from Reference 2 but was re-optimized using M06-2X/6-31+G(d,p), and all trajectory simulations were 
initialized with this geometry. Quasi-classical microcanonical simulations were performed for three different microcanonical energies, $\mathrm{E}_{\mathrm{TS}, \text { micro }}=1 \mathrm{kcal} / \mathrm{mol}, 10 \mathrm{kcal} / \mathrm{mol}$, and $40 \mathrm{kcal} / \mathrm{mol}$ above the zeropoint corrected barrier height. The maximum time step was less than $1 \mathrm{fs}$, with this value chosen on the basis of convergence tests. Roughly 200 trajectories were performed for each microcanonical energy. The trajectories were terminated when either (i) the center of mass separation between $\mathrm{OQ}^{\prime} \mathrm{OOH}$ and $\mathrm{OH}$ exceeded $8 \mathrm{bohr}$, or (ii) the distance between the two fragmenting oxygen atoms exceeded $10 \mathrm{bohr}$. The final time was typically on the order of 100-200 fs. A small percentage of the trajectories crashed before both termination criteria were satisfied. Inspection of those jobs revealed that fragmentation had occurred, but that the spatial degeneracy in the $2 \mathrm{p}$ orbitals in $\mathrm{OH}$ prevented the reference wave function from converging in the SCF calculation. These crashed jobs were nonetheless included in the final analysis, since this orbital degeneracy problem only occurs when the $\mathrm{OH}$ are $\mathrm{OQ}^{\prime} \mathrm{OOH}$ sufficiently far apart (e.g. 4-5 $\AA$ ) that the energy distributions have stabilized. Other trajectories failed to complete because the reaction proceeded in the reverse direction, i.e. back to $\mathrm{O}_{2} \mathrm{QOOH}$. Such trajectories were omitted from the final analysis.

At each time step, the Cartesian coordinates of the $\mathrm{OQ}^{\prime} \mathrm{OOH}$ and $\mathrm{OH}$ fragments were extracted from the log file, and new single-point calculations for the isolated fragments were performed. The potential energy, kinetic energy, and angular momentum for each fragment were determined as a function of time, as were the interaction potential and the relative translational energy between the two fragments. Conservation of total energy and total angular momentum was confirmed. For each trajectory, once the absolute value of the interaction potential was effectively zero (e.g. less than $0.1 \mathrm{kcal} / \mathrm{mol}$ ), the total energy in $\mathrm{OQ}^{\prime} \mathrm{OOH}, \mathrm{OH}$, and relative translation each became invariant with time, see Figure 2.

For the $\mathrm{C}_{3} \mathrm{H}_{6} \mathrm{O}_{3}$ PES, the initial stationary point geometries were taken from Reference 6 . These geometries were recomputed using a hybrid coupled cluster / MP2 approach, in which the following energy, $E_{C C, M P 2}$, was used in the geometry optimization and frequency calculations: 


$$
E_{\mathrm{CC}, \mathrm{MP} 2}=E_{\mathrm{CCSD}(\mathrm{T}) / \mathrm{cc}-\mathrm{pvdz}}+E_{\mathrm{MP} 2 / \mathrm{cc}-\mathrm{pvtz}}-E_{\mathrm{MP} 2 / \mathrm{cc}-\mathrm{pvdz}}
$$

The electronic energies were further refined by single-point calculations using RCCSD(T)-F12b/ccpVTZ-F12, the same method used in Reference [6]. The results do not differ significantly from those reported in Reference [6]. All coupled-cluster and MP2 calculations were performed using MOLPRO [13]. For all stationary points on the $\mathrm{C}_{3} \mathrm{H}_{6} \mathrm{O}_{3}$ PES, except $\mathrm{OQ}^{\prime} \mathrm{OOH}$, there were at most two internal rotors. These torsional modes were treated as coupled, and a relaxed multi-dimensional torsional surface was computed using M06-2X/6-31+G(d,p) in $10^{\circ}$ increments. OQ'OOH, in contrast, has four torsional modes. The global minimum structure for $\mathrm{OQ}^{\prime} \mathrm{OOH}$ is quasi-cyclic and exhibits a strong degree of hydrogen bonding between the $\mathrm{CHO}$ and $\mathrm{OOH}$ groups; therefore, the four torsional modes are coupled. However, a quantum treatment of the complete four-dimensional rotational surface was computationally prohibitive. Instead, the two terminal torsional modes (i.e. $\mathrm{O}^{1} \mathrm{C}^{2} \mathrm{C}^{3} \mathrm{C}^{4}$ and $\mathrm{C}^{4} \mathrm{O}^{5} \mathrm{O}^{6} \mathrm{H}$, where the superscript indicates index of the heavy atom) were treated as coupled, and the two internal torsional modes (i.e. $\mathrm{C}^{2} \mathrm{C}^{3} \mathrm{C}^{4} \mathrm{O}^{5}$ and $\mathrm{C}^{3} \mathrm{C}^{4} \mathrm{O}^{5} \mathrm{O}^{6}$ ) were treated as uncoupled. Although a $4 \mathrm{D}$ model would be preferred, we believe the inclusion of the $2 \mathrm{D}$ rotor captures the essential physics of the coupled $\mathrm{COOH}$ rotation.

\section{master equation}

The final internal energy in $\mathrm{OQ}^{\prime} \mathrm{OOH}$ was extracted from each trajectory simulation. The results were collected into population distributions for each microcanonical transition state energy, and a Gaussian function was fit to each population distribution.

$$
\alpha_{5 * \rightarrow 5 a *}(X, E)=\frac{e^{-\frac{\left(E-\mu_{X}\right)^{2}}{2 \sigma_{X}^{2}}}}{\sigma_{X} \sqrt{2 \pi}}
$$

where $\mu_{X}$ and $\sigma_{X}$ are the mean and standard deviation of the initial $\mathrm{OQ}^{\prime} \mathrm{OOH}(\mathrm{E})$ population distribution for microcanonical transition state energy $\mathrm{E}_{\mathrm{TS} \text {,micro }}=X$, and the nomenclature for $\alpha_{5 * \rightarrow 5 a *}(X, E)$ is chosen to maintain consistency with Reference [10]. A linear mapping was created from the microcanonical transition state energy to the population distribution of $\mathrm{OQ}^{\prime} \mathrm{OOH}$ [14] (e.g. Eq 4 below). 
The RRKM/ME rate constants were computed using PAPER [9]. A novel feature of this code is the ability to derive phenomenological rate constants for reactive intermediates with arbitrary (e.g. nonBoltzmann) population distributions. For internally excited intermediates, such as hot $\mathrm{OQ}^{\prime} \mathrm{OOH}$, the code determines what fraction of that intermediate is stabilized to a thermal distribution and what fraction undergoes direct chemical reaction. It does so by projecting the initial population distribution onto the eigenstates of the master equation [8]. In the present work, the energy-resolved population of $\mathrm{OQ}^{\prime} \mathrm{OOH}$ in the master equation was initialized with a delta function centered at a specific energy bin, and the probability of the reactive complex with that initial energy distribution being captured by one of the wells or yielding bimolecular products was computed. This process was repeated with a different delta function for each of the energy bins, thereby providing an array of branching fractions $\hat{\alpha}_{5 a^{*} \rightarrow j}(E)$ for the production of the different product channels $j$ from a given $\mathrm{OQ}^{\prime} \mathrm{OOH}(\mathrm{E})$ state. The five possible values for $j$ are: thermal $\mathrm{OQ}^{\prime} \mathrm{OOH}$, thermal $\mathrm{CP}$, $\mathrm{OQ}^{\prime} \mathrm{O}+\mathrm{OH}, \mathrm{HCOOH}+\mathrm{CH}_{3} \mathrm{CHO}$, and $\mathrm{CH}_{3} \mathrm{COOH}+$ $\mathrm{CH}_{2} \mathrm{O}$. The convolution of this array with the population distribution of excited $\mathrm{OQ}^{\prime} \mathrm{OOH}(\mathrm{E})$ gives an effective branching fraction for each of the five possible product channels from a single microcanonical $\mathrm{TS}_{1}$ energy:

$$
\hat{\alpha}_{5 * \rightarrow j}(X)=\int_{0}^{\infty} \alpha_{5 * \rightarrow 5 a *}(X, E) \hat{\alpha}_{5 a^{*} \rightarrow j}(E) d E
$$

where $\hat{\alpha}_{5^{*} \rightarrow j}(X)$ is the final branching fraction for microcanonical transition state energy $X$ going to product $j$. Further, the abovementioned quantities, $\alpha_{5 * \rightarrow 5 a *}(X, E)$ and $\hat{\alpha}_{5 a * \rightarrow j}(E)$, can be incorporated into a methodology for coupling multiple master equations and calculating effective phenomenological rate constants for sets of thermal reactants (e.g. $\mathrm{O}_{2}+\mathrm{R}+\mathrm{O}_{2}$ or $\mathrm{O}_{2}+\mathrm{QOOH}$ ) to sets of thermal products, as discussed in the companion paper [10].

For both the thermal and non-thermal $\mathrm{OQ}^{\prime} \mathrm{OOH}$ calculations, the average collisional energy transfer was given by $\Delta \mathrm{E}_{\mathrm{down}}=300(\mathrm{~T} / 298)^{0.85} \mathrm{~cm}^{-1}$ for $\mathrm{He}[15]$ and $300(\mathrm{~T} / 298)^{0.75} \mathrm{~cm}^{-1}$ for $\mathrm{N}_{2}[15]$; the 
Lennard-Jones parameters were $\varepsilon=6.95 \mathrm{~cm}^{-1}$ and $\sigma=2.55 \AA$ for $\mathrm{He}[16], \varepsilon=57.0 \mathrm{~cm}^{-1}$ and $\sigma=3.74 \AA$ for $\mathrm{N}_{2}[16]$, and $\varepsilon=285.2 \mathrm{~cm}^{-1}$ and $\sigma=5.18 \AA$ for $\mathrm{C}_{3} \mathrm{H}_{6} \mathrm{O}_{3}[2]$.

\section{Results}

Table 1: Zero-point corrected electronic energies for $\mathrm{C}_{3} \mathrm{H}_{6} \mathrm{O}_{3} \mathrm{PES}$, relative to $\mathrm{OQ}^{\prime} \mathrm{OOH}$.

\begin{tabular}{|c|c|c|}
\hline Species & $\begin{array}{l}\text { Energy } \\
{[\mathrm{kcal} / \mathrm{mol}]}\end{array}$ & T1 diagnostic \\
\hline $\mathrm{HOOCH}_{2} \mathrm{CH}_{2} \mathrm{CHO}$ & 0.0 & 0.014 \\
\hline $\mathrm{c}-\mathrm{CH}(\mathrm{OH}) \mathrm{OOCH}_{2} \mathrm{CH}_{2}$ & -8.0 & 0.013 \\
\hline $\mathrm{OCH}_{2} \mathrm{CH}_{2} \mathrm{CHO}+\mathrm{OH}$ & 43.8 & $0.018,0.008$ \\
\hline $\mathrm{HCOOH}+\mathrm{CH}_{3} \mathrm{CHO}$ & -68.4 & $0.016,0.014$ \\
\hline $\mathrm{CH}_{3} \mathrm{COOH}+\mathrm{CH}_{2} \mathrm{O}$ & -67.8 & $0.014,0.015$ \\
\hline $\mathrm{TS}: \mathrm{OQ}^{\prime} \mathrm{OOH} \rightleftharpoons \mathrm{CP}$ & 32.6 & 0.017 \\
\hline $\mathrm{TS}: \mathrm{CP} \rightleftharpoons \mathrm{HCOOH}$ & 25.6 & 0.028 \\
\hline $\mathrm{TS}: \mathrm{CP} \rightleftharpoons \mathrm{CH}_{3} \mathrm{COOH}$ & 27.9 & 0.028 \\
\hline
\end{tabular}

The zero-point corrected electronic energies for the $\mathrm{C}_{3} \mathrm{H}_{6} \mathrm{O}_{3}$ PES are provided in Table 1. The $\mathrm{RRKM} / \mathrm{ME}$ rate constants for the thermal decomposition of $\mathrm{HOOCH}_{2} \mathrm{CH}_{2} \mathrm{CHO}$ were computed over a temperature range of 300 to $1500 \mathrm{~K}$ and a pressure range of 0.01 to $100 \mathrm{~atm}$. The branching fraction as a function of temperature and pressure for the four different product channels starting from $\mathrm{OQ}^{\prime} \mathrm{OOH}$ are presented in Figure 3. For the lowest temperatures, the dominant pathway for $\mathrm{OQ}^{\prime} \mathrm{OOH}$ is cyclization to c- $\mathrm{CH}(\mathrm{OH}) \mathrm{OOCH}_{2} \mathrm{CH}_{2}$. By $450 \mathrm{~K}$, the chain branching pathway $\left(\mathrm{OCH}_{2} \mathrm{CH}_{2} \mathrm{CHO}+\mathrm{OH}\right)$ is the dominant channel. Of the two carboxylic acid channels, the rate constant for $\mathrm{HCOOH}+\mathrm{CH}_{3} \mathrm{CHO}$ is about an order of magnitude larger than for $\mathrm{CH}_{3} \mathrm{COOH}+\mathrm{CH}_{2} \mathrm{O}$. The $\mathrm{HCOOH}+\mathrm{CH}_{3} \mathrm{CHO}$ is competitive with the main two channels only at the lowest pressures; for 1 atm and above, the carboxylic acid channels are less than $1 \%$ of the total branching ratio. Although the two carboxylic acid channels exhibit considerable pressure dependence, the $\mathrm{CP}$ and $\mathrm{OQ}^{\prime} \mathrm{O}+\mathrm{OH}$ channels do not. For temperatures greater than $600 \mathrm{~K}$, the flux through the ring-closing transition state is negligible, accounting for $\sim 4 \%$ of the 
total decomposition rate constant at $0.01 \mathrm{~atm}$ and $<1 \%$ for $1 \mathrm{~atm}$ and higher. Under these conditions, the CP-to-carboxylic-acid pathway - whether sequential or direct - is not expected to have a significant impact on first-stage ignition, as predicted in [6]. However, for sub-atmospheric pressure experiments below $600 \mathrm{~K}$, the sequential and direct pathways to carboxylic acid are expected to be significant and should be included in the kinetic mechanism.

Figure 2 shows a typical result from a single direct dynamics simulation. The solid red, blue, and black lines correspond to the total $\mathrm{OQ}^{\prime} \mathrm{OOH}$, total $\mathrm{OH}$, and relative translational energy, respectively. The dashed and dotted red lines correspond to the potential and kinetic energy in $\mathrm{OQ}^{\prime} \mathrm{OOH}$, respectively, which are appropriately out of phase. For simplicity, the interaction potential between the $\mathrm{OQ}^{\prime} \mathrm{OOH}$ and $\mathrm{OH}$ fragments prior to dissociation is not included.

Plots of the normalized population distributions from the trajectory simulations are shown in Figure 4. The blue, red, and green population distributions correspond to $\mathrm{E}_{\mathrm{TS} \text {,micro }}=1$, 10, and 40 kcal/mol, respectively. The corresponding Gaussian functions are shown by the solid lines in Figure 4; the fitted means were $-18.5,-10.9$, and $11.3 \mathrm{kcal} / \mathrm{mol}$ relative to the dissociation limit for $\mathrm{OQ}^{\prime} \mathrm{OOH}$, respectively, and the standard deviations were $6.4,7.0$, and $13.7 \mathrm{kcal} / \mathrm{mol}$, respectively. The linear mapping from the microcanonical transition state energy to the population distribution of $\mathrm{OQ}^{\prime} \mathrm{OOH}$ (again relative to the dissociation limit for $\mathrm{OQ}^{\prime} \mathrm{OOH}$ ) is provided in Equation 4, with $\mathrm{R}^{2}=0.99$ in each case.

$$
\begin{gathered}
\mu_{X}=-18.9+0.8 \times E_{T S, \text { micro }} \\
\sigma_{X}=5.6+0.2 \times E_{T S, \text { micro }}
\end{gathered}
$$

The bin width in Figure 4 is $2 \mathrm{kcal} / \mathrm{mol}$. The number of trajectories for each energy $\mathrm{E}_{\mathrm{TS} \text {,micro }}$ was increased until the linear fits for the mean and standard deviation did not change with changing bin size,

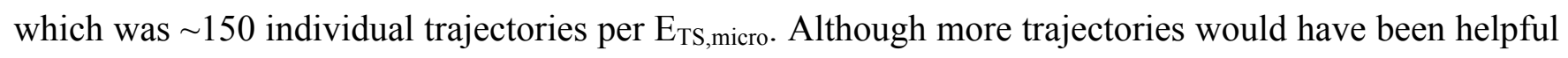
in establishing better statistics, the computational cost of each trajectory made such an analysis prohibitive. 
In addition to the standard RRKM/ME calculations to determine the phenomenological rate constants, a separate set of calculations was performed to compute the branching fractions for hot $\mathrm{OQ}^{\prime} \mathrm{OOH}$. Equation 4 allows us to approximate the population distribution for any arbitrary microcanonical energy in $\mathrm{TS}_{1}$. For simplicity, we have chosen three energies: $\mathrm{E}_{\mathrm{TS} \text {,micro }}=0.0,12.3$, and $30.4 \mathrm{kcal} / \mathrm{mol}$. The value of $12.3 \mathrm{kcal} / \mathrm{mol}$ corresponds to the difference in energy between the transition state and $\mathrm{O}_{2}+\mathrm{QOOH}$; similarly, $30.4 \mathrm{kcal} / \mathrm{mol}$ corresponds to the difference in energy between the transition state and $\mathrm{O}_{2}+\mathrm{R}+\mathrm{O}_{2}$. Together, these three values give a reasonable approximation to the energy spread leaving $\mathrm{TS}_{1}$ for thermal decomposition of $\mathrm{O}_{2} \mathrm{QOOH}, \mathrm{O}_{2}+$ thermal $\mathrm{QOOH}$, and $\mathrm{O}_{2}+$ hot QOOH.

The results for $\hat{\alpha}_{5^{*} \rightarrow j}\left(E_{T S, \text { micro }}\right)$ for $\mathrm{E}_{\mathrm{TS}, \text { micro }}=0.0,12.3$, and $30.4 \mathrm{kcal} / \mathrm{mol}$ are shown in Figure 5a-c, respectively. The branching fraction for thermal $\mathrm{OQ}^{\prime} \mathrm{OOH}$ is shown in black, and the branching fraction for $\mathrm{OCH}_{2} \mathrm{CH}_{2} \mathrm{CHO}+\mathrm{OH}$ (“OQ'O $+\mathrm{OH}^{\prime}$ ) is shown in red. For simplicity, the $\mathrm{CP}$ and the two carboxylic acid channels are lumped together into a single channel "other", shown in blue. For $\mathrm{E}_{\mathrm{TS} \text {, micro }}=$ $0.0 \mathrm{kcal} / \mathrm{mol}$, more than $99 \%$ of the hot $\mathrm{OQ}^{\prime} \mathrm{OOH}$ is stabilized to thermal OQ'OOH. The branching fraction for the chain branching pathway increases as (i) the microcanonical transition state energy is increased, (ii) the temperature is increased, and (iii) the pressure is decreased, with a maximum value of $51 \%$ at 0.01 atm and $1200-1500 \mathrm{~K}$ for $\mathrm{E}_{\mathrm{TS}, \text { micro }}=30.4 \mathrm{kcal} / \mathrm{mol}$.

Since one would expect the highest distribution of microcanonical energies in $\mathrm{TS}_{1}$ at low pressures and high temperatures, potential for direct decomposition of nascent $\mathrm{OQ}^{\prime} \mathrm{OOH}$ prior to stabilization will be higher at those conditions. However, as the temperature increases, the equilibrium constants for $\mathrm{R}+\mathrm{O}_{2} \rightarrow \mathrm{RO}_{2}$ and $\mathrm{O}_{2}+\mathrm{QOOH} \rightarrow \mathrm{O}_{2} \mathrm{QOOH}$ shift back towards the bimolecular reactants (signaling the end of the low-temperature kinetics regime), so the entire OQ'OOH pathway will become less significant. Moreover, at higher pressures relevant for engine conditions, the contribution of hot $\mathrm{OQ}^{\prime} \mathrm{OOH}$ to the total rate of chain branching will be lower, since virtually all of the hot OQ'OOH will be thermalized before it can dissociate. However, many mechanisms are validated against low-pressure 
experiments that attempt to isolate specific oxidation reactions, and the effects of hot $\mathrm{OQ}^{\prime} \mathrm{OOH}$ can be significant in those conditions. Failure to account for these effects when optimizing a mechanism against low-pressure data may lead to spurious extrapolations for high-pressure conditions.

\section{Conclusions}

The temperature and pressure dependent rate constants for the thermal decomposition of a ketohydroperoxide, $\mathrm{HOOCH}_{2} \mathrm{CH}_{2} \mathrm{CHO}$, to four product channels were computed. Below $400 \mathrm{~K}$, the dominant products are $\mathrm{c}-\mathrm{CH}(\mathrm{OH}) \mathrm{OOCH} 2 \mathrm{CH} 2$ and $\mathrm{HCOOH}+\mathrm{CH}_{3} \mathrm{CHO}$. Above $600 \mathrm{~K}$, the chain branching channel $\mathrm{OCH}_{2} \mathrm{CH}_{2} \mathrm{CHO}+\mathrm{OH}$ is the only significant product.

Direct dynamics calculations were initiated at the transition state for $\mathrm{OOCH}_{2} \mathrm{CH}_{2} \mathrm{CH}_{2} \mathrm{OOH} \rightarrow$ $\mathrm{HOOCH}_{2} \mathrm{CH}_{2} \mathrm{CHOOH}$. The distribution of total internal energy in the ketohydroperoxide fragment was determined as a function of the microcanonical energy in the transition state. The master equation was solved for different initial energy-resolved populations of the OQ'OOH adduct, which provided the probability of a OQ'OOH with a specific internal energy ending up in one of five possible unimolecular or bimolecular products. These probabilities were convoluted with the population distribution of the $\mathrm{OQ}^{\prime} \mathrm{OOH}$ from the direct dynamics calculations to obtain branching fractions for specific product channels for a given microcanonical transition state energy.

The results suggest that the majority of internally excited ketohydroperoxide will be quenched into a thermal distribution. At high internal energies and low pressures, a significant fraction of the hot $\mathrm{OQ}^{\prime} \mathrm{OOH}$ will decompose rather than thermalize. Proper interpretation of low-pressure experiments may require inclusion of hot intermediates, particularly if a chemical kinetic mechanism is optimized against the low-pressure data. At engine relevant pressures, however, the role of hot $\mathrm{OQ}^{\prime} \mathrm{OOH}$ is expected to be less significant. Under those conditions, the sequential pathway for low-temperature oxidation $\left(\mathrm{R}+\mathrm{O}_{2}\right.$ $\left.\rightarrow \mathrm{RO}_{2} \rightarrow \mathrm{QOOH}, \mathrm{O}_{2}+\mathrm{QOOH} \rightarrow \mathrm{O}_{2} \mathrm{QOOH} \rightarrow \mathrm{OQ}^{\prime} \mathrm{OOH}+\mathrm{OH} \rightarrow \mathrm{OQ}^{\prime} \mathrm{O}+2 \mathrm{OH}\right)$ is expected to be the dominant pathway for chain branching, with activated processes playing a comparatively minor role.

\section{Supplemental Material}


The pressure-dependent rate coefficients for $\mathrm{HOOCH}_{2} \mathrm{CH}_{2} \mathrm{CHO}$ decomposition are provided for both $\mathrm{He}$ and $\mathrm{N}_{2}$ in CHEMKIN PLOG format.

\section{Acknowledgments}

This work was supported by the Division of Chemical Sciences, Geosciences, and Biosciences, the Office of Basic Energy Sciences, the U.S. Department of Energy, under contract number DE-AC0494-AL85000 as part of the Argonne-Sandia Consortium on High-Pressure Combustion Chemistry (FWP

\# 59044). CFG and MPB gratefully acknowledge financial support from the Argonne Director's Postdoctoral Fellowship. 


\section{Figures}

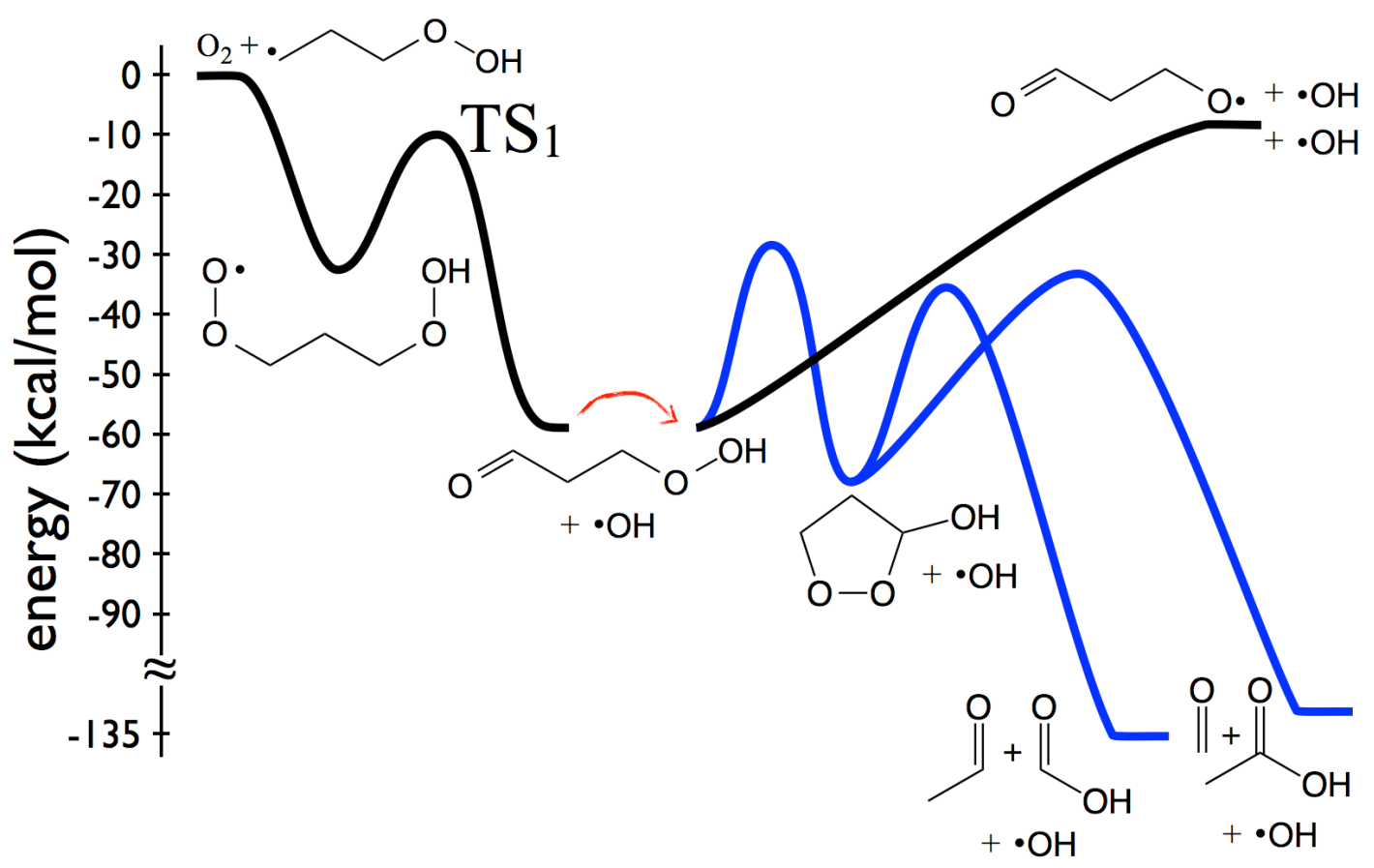

Figure 1: Combined $\mathrm{C}_{3} \mathrm{H}_{7} \mathrm{O}_{4}$ and $\mathrm{C}_{3} \mathrm{H}_{6} \mathrm{O}_{3}(+\mathrm{OH})$ potential energy surfaces. The chain branching pathway is shown in black; the Korcek pathway is shown in blue. Direct dynamics simulations were initiated from $\mathrm{TS}_{1}$.

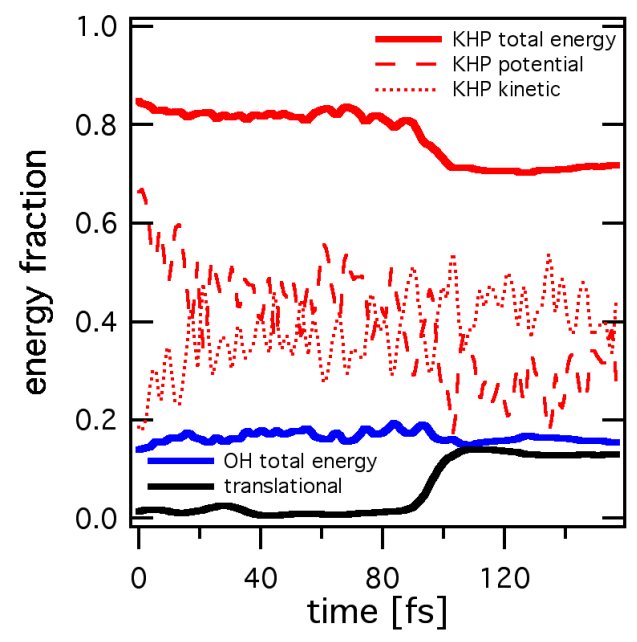

Figure 2: Typical result for a single direct dynamics simulation, which depicts the fraction of the total energy in the transition state that is converted into ketohydroperoxide (red), $\mathrm{OH}$ (blue), and relative translational energy (black). The dashed and dotted lines are the potential and kinetic energy of $\mathrm{OQ}^{\prime} \mathrm{OOH}$, respectively. 


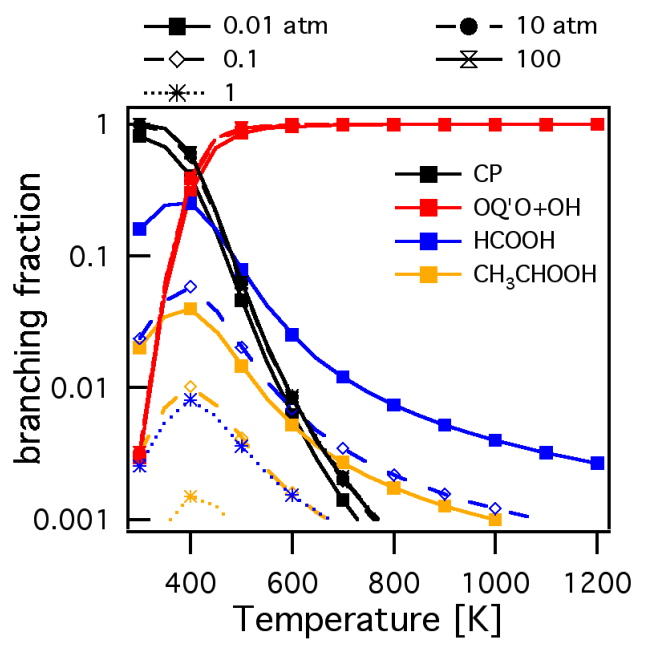

Figure 3: Branching fraction for the RRKM/ME rate constants for thermal $\mathrm{HOOCH}_{2} \mathrm{CH}_{2} \mathrm{CHO}$ decomposition at five different pressures. For clarity, only the acid is shown in the legend for the two carboxylic acid + carbonyl channels.

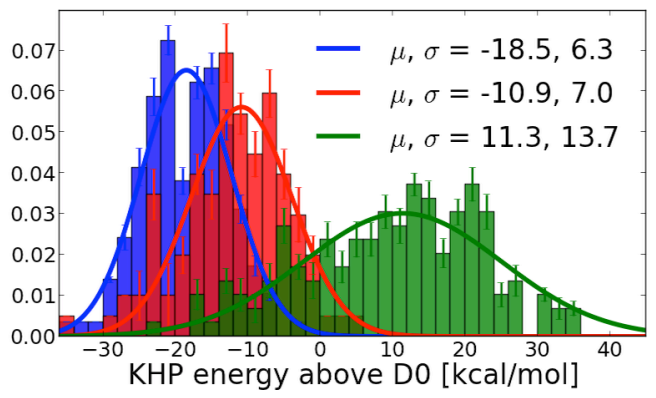

Figure 4: Population distributions for the internal energy in $\mathrm{OQ}^{\prime} \mathrm{OOH}$, normalized so that the sum over each color equals unity. The zero of energy corresponds to dissociation limit. The blue, red, and green histograms correspond to $\mathrm{E}_{\mathrm{TS} \text {,micro }}=1,10$, and $40 \mathrm{kcal} / \mathrm{mol}$, respectively. The solid lines correspond to the Gaussian fits. 


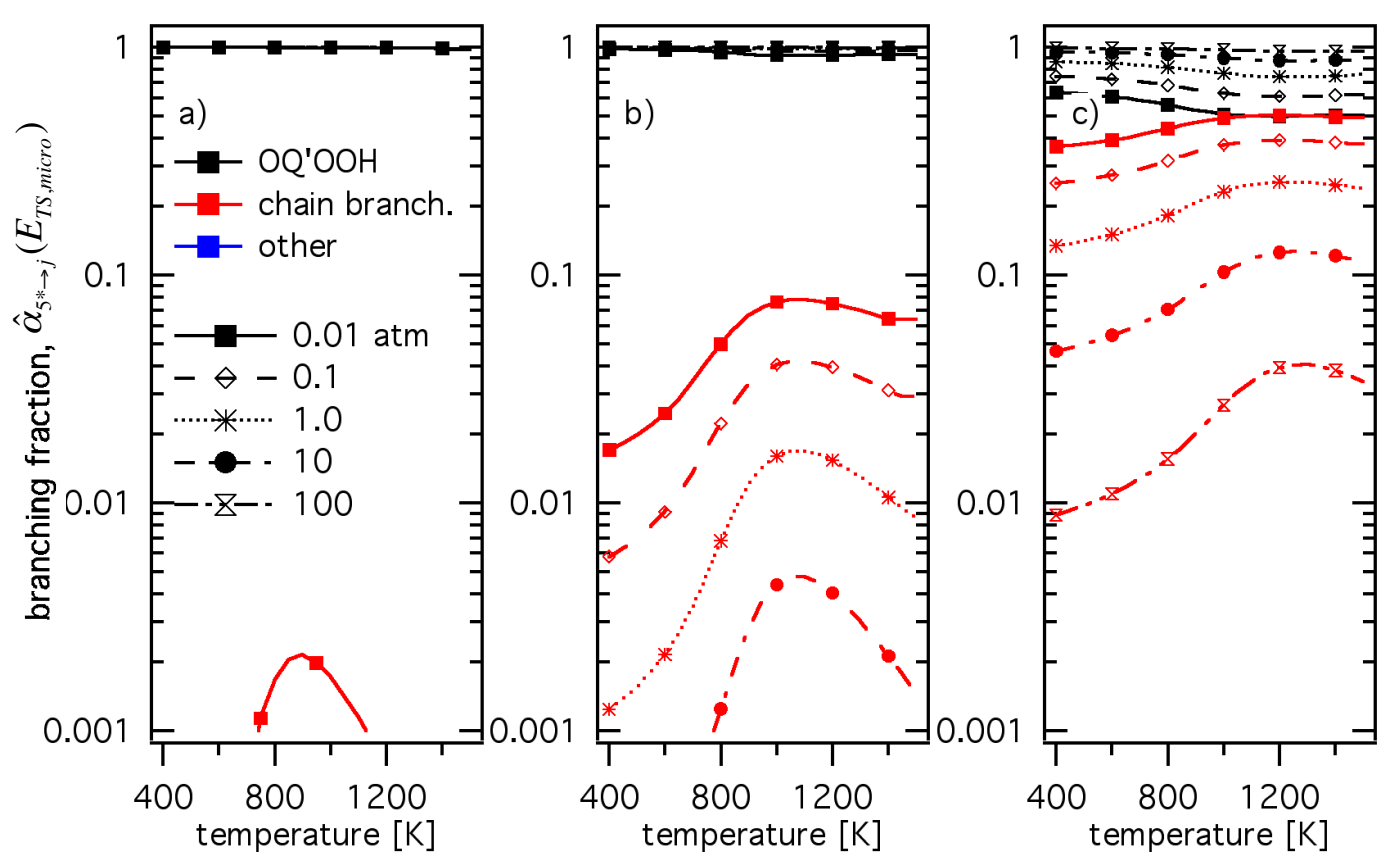

Figure 5: Branching fractions $\hat{\alpha}_{5^{*} \rightarrow j}\left(E_{T S, \text { micro }}\right)$ for hot $\mathrm{OQ}^{\prime} \mathrm{OOH}$ emerging from $\mathrm{TS}_{1}$ at five pressures and three microcanonical energies for $\mathrm{TS}_{1}$. (a) $\mathrm{E}_{\mathrm{TS} \text {,micro }}=0.0 \mathrm{kcal} / \mathrm{mol}$, (b) $\mathrm{E}_{\mathrm{TS}, \text { micro }}=12.3 \mathrm{kcal} / \mathrm{mol}$, (c) $\mathrm{E}_{\mathrm{TS}, \text { micro }}=30.4 \mathrm{kcal} / \mathrm{mol}$, relative to the classical barrier height. 


\section{References}

[1] J. Zádor, C.A. Taatjes, R. X. Fernandes, Prog. Energy Combust. Sci. 37 (2011) 371-421.

[2] C.F. Goldsmith, W.H. Green, S.J. Klippenstein, J. Phys. Chem. A 116 (2012) 3325-3346.

[3] S.S. Merchant, C.F. Goldsmith, M.P. Burke, S.J. Klippenstein, W.H. Green, In Progress.

[4] J. C. Keck, H. Hu, Proc. Comb. Inst. 21 (1986) 521-529.

[5] M.P. Burke, C.F. Goldsmith, S.J. Klippenstein, O. Welz, H. Huang, I.O Antonov, J.D. Savee, D.L. Osborn, J. Zádor, C.A. Taatjes, L. Sheps, In Progress.

[6] A. Jalan, I.M. Alecu, R. Meana-Pañeda, J. Aguilera-Iparraguirre, K.R. Yang, S.S. Merchant, D.G. Truhlar, W.H. Green, J. Am. Chem. Soc. 135 (2013) 11100-11114.

[7] E.J. Hamilton, S. Korcek, L.R. Mahoney, Int. J. Chem. Kin. 12 (1980) 577-603.

[8] Y. Georgievskii, J.A. Miller, M.P. Burke, S.J. Klippenstein, J. Phys. Chem. A 117 (2013) 1214612154.

[9] Y. Georgievskii, A. W. Jasper, J. Zador, J. A. Miller, M. P. Burke, C. F. Goldsmith, and S. J. Klippenstein, PAPER, v1, unpublished (2014).

[10] M.P. Burke, C.F. Goldsmith, Y. Georgievskii, S.J. Klippenstein, Proc. Comb. Inst. 35 (2014) submitted.

[11] Y. Zhao, D.G. Truhlar, Theor. Chem. Act. 120 (2008) 215-241.

[12] Gaussian 09, Revision A.02, M.J. Frisch et al, Gaussian, Inc., Wallingford CT, 2009.

[13] MOLPRO, version 2012.1, H.-J. Werner et al, see http://www.molpro.net.

[14] L. Sun, W.L. Hase, J. Chem. Phys. 121 (2004) 8831-8845.

[15] A.W. Jasper, J.A. Miller J. Phys. Chem. A 115 (2011) 6438-6455.

[16] H. Hippler, J. Troe, H.J. Wendelken, J. Chem. Phys. 78 (1983) 6709-6717. 